\title{
Further hearing loss during osteoporosis treatment with etidronate
}

\author{
Dokuz Eylül \\ University, Medical \\ Faculty, İnciraltr, \\ İzmir, Turkey \\ Department of \\ Internal Medicine, \\ Division of \\ Endocrinology and \\ Metabolism \\ $S$ Yeşil \\ A Çömlekçi \\ Department of \\ Otolaryngology \\ A Güneri \\ Correspondence to \\ Abdurrahman Cömlekçi, \\ $\mathrm{MD}$, Camtepe Mh, Yildırım \\ Sk, Kuranşal Sitesi No 31/9, \\ Narlıdere, İzmir, 35320 \\ Turkey
}

Accepted 21 January 1998

\author{
Sena Yeşil, Abdurrahman Çömlekçi, Ataman Güneri
}

\begin{abstract}
Summary
Ototoxicity is a rare and disabling complication in bisphosphonate therapy. Here we describe two patients who encountered further hearing loss during oral etidronate treatment for osteoporosis.
\end{abstract}

Keywords: ototoxicity; bisphosphonates; etidronate; adverse drug reaction

Controlled clinical trials have shown that bisphosphonates can increase vertebral bone mass, both in postmenopausal (primary) ${ }^{1}$ and secondary osteoporosis. ${ }^{2}$ The toxicity of bisphosphonates is low. ${ }^{3}$ Etidronate is being widely used throughout the world in various clinical conditions. ${ }^{24}$ Ototoxicity is a hitherto unreported side-effect with etidronate.

\section{Case reports}

Case 1

A 66-year-old woman with otosclerosis and hyperthyroidism was being treated with oral etidronate for osteoporosis. She had had two cycles of intermittent cyclic etidronate therapy consisting of etidronate $400 \mathrm{mg}$ daily for 14 days followed by calcium for 76 days. She had taken a total dose of approximately $12 \mathrm{~g}$ in 5 months.

Otosclerosis had been diagnosed 15 years before and she had had a stapedectomy operation at that time. Since then, she had heard well enough to continue normal daily activities. However, after the second etidronate cycle, she complained of severe tinnitus and almost complete hearing loss. She was not taking any other medication, except for propylthiouracil for Graves' disease.

Examination in the fifth month of therapy revealed no visible abnormality of the nose, mouth, ears, pharynx, or central nervous system. Pure tone audiometry showed severe bilateral high-tone sensorineural hearing loss. During follow-up, her tinnitus and hearing loss persisted.

\section{Case 2}

A 65-year-old woman had been diagnosed as otosclerotic and operated on at the age of 30 years. Since then she had had hearing problems only with the ear that had not been operated on. She was prescribed intermittent cyclic etidronate therapy consisting of etidronate 400 $\mathrm{mg}$ per day for 14 days followed by calciumplus-calcitriol, $250 \mu \mathrm{g}$ per day for 76 days, for osteoporosis.
After the second etidronate cycle the patient said she had stopped taking the etidronate because of an increase in tinnitus and difficulty in hearing. The total dose she had taken in 6 months was approximately $12 \mathrm{~g}$. Examination revealed no visible abnormality of the nose, mouth, ears, pharynx, or central nervous system. Pure tone audiometry showed moderate sensorineural hearing loss in the operated ear and severe sensorineural hearing loss in the other ear. During follow-up, her tinnitus and hearing loss persisted.

\section{Discussion}

These two women had symptoms and objective evidence of ototoxicity temporally related to etidronate therapy. Their history of otosclerosis may have predisposed them to this adverse effect. We could find only two case reports of ototoxicity after bisphosphonate therapy in the literature. Boumans described two patients treated with pamidronate $(15 \mathrm{mg} /$ day intravenously for 2 weeks followed by oral treatment for 3 months at $150 \mathrm{mg}$ daily) for otosclerosis. These patients showed ototoxicity approximately one year after pamidronate therapy. The second case reported concerns a patient who received six intravenous infusions of pamidronate $60 \mathrm{mg}$, each given over two hours at $2-3$ day intervals for Paget's disease. ${ }^{6}$ This patient had a history of tinnitus and experienced ototoxicity after the second infusion. Our patients are the first cases described with ototoxicity related to etidronate administration.

The common feature of these reported patients is pre-existing otosclerosis. The pathogenesis of otosclerosis is still not clear. This autosomal dominant inherited condition seems to initiate an autoimmune process against type II collagen in the cartilaginous remnants in the otic capsule. ${ }^{7}$ In the ensuing lytic process, many mononuclear phagocytes (histiocytes) are present, with numerous lysosomes and osteoclasts. ${ }^{8}$ It is widely accepted that otosclerosis causes sensorineural hearing loss in patients whose cochleas are severely affected by the disease. ${ }^{9}$ In these patients, lamellar bone is removed by osteoclasts and replaced by woven spongiotic bone of greater thickness, cellularity and vascularity. This process is followed by remodelling to form lamellar (sclerotic) bone and mineralization

Bisphosphonates such as pamidronate and etidronate have been tried in the treatment of 


\section{Toxicity of bisphosphonates \\ - bisphosphonates have low toxicity, gastrointestinal side-effects occurring in a few patients. Rapid intravenous administration may cause renal failure, and administration of aminobisphosphonates is sometimes associated with transient fever and leucopenia \\ - long-term side-effects of potential concern include defective mineralization of bone and low bone turnover, both of which may adversely affect bone strength. The frequency and severity of these effects vary with different bisphosphonates \\ - bisphosphonates may cause hearing deterioration in patients with otosclerosis \\ - ototoxicity in susceptible patients during bisphosphonate therapy may occur not only in the acute phase but also long term}

Box 1

otosclerosis. ${ }^{510}$ Although their mechanism of action remains obscure, it seems reasonable to propose that inhibition of bone turnover in the cochlea by bisphosphonates would prevent hearing loss and disease activity. In practice, this response is not observed. One explanation is that the decrease in bone resorption is not immediately followed by the 'couplinginduced' diminution of formation, bringing only a temporary gain in calcium balance through the reduction of the so-called remodelling space. ${ }^{11}$ This osteoblastic bone gain in the cochlea may cause sensorineural hearing loss in patients with otosclerosis.

In previous reports, patients experiencing ototoxicity presumably had higher postinfusion drug peak levels which made them more vulnerable to toxicity. The bioavailability of an oral dose of bisphosphonate is under $10 \%{ }^{12}$; whatever their serum levels, bisphosphonates are rapidly cleared from plasma and nonosseous tissues, both by sequestration

1 Reid IR, Wattie DJ, Evans MC, Gamble GD, Stapleton JP, Cornish J. Continuous therapy with pamidronate, a poten bisphosphonate, in postmenopausal osteoporosis. $\not{J}$ Cli Endocrinol Metab 1994;79:1595-9.

2 Struys A, Snelder AA, Mulder H. Cyclical etidronate reverses bone loss of spine and proximal femur in patients with established corticosteroid-induced osteoporosis. $A m$ Med 1995;99:235-42.

3 Compston JE. The therapeutic use of bisphosphonates BMF 1994;309:711-5.

4 Dewis P, Prasad BK, Anderson DC, Willets S. Clinical experience with the use of two diphosphonates in the treatment of Paget's disease. Ann Rheumatol Dis 1985;44:34-8

5 Boumans LJ, Poublon RM. The detrimental effect of Boumans LJ, Poublon RM. The detrimental effect of
aminohydroxypropylidene biphosphonate (APD) in otaminohydroxypropylidene biphosphonate (APD) in ot6 ospongiosis. Eur Arch Otorhinolaryngol 1991;248:218-21.

6 Reid IR, Mills DAJ, Wattie DJ. Ototoxicity associated with intravenous biphosphonate administration. Calcif Tissue In 1995;56:584-5.

Yoo TJ. Etiopathogenesis of otosclerosis: a hypothesis. Ann Otol Rhinol Laryngol 1984;93:28-33.
Structure, effects, and pharmacokinetics of bisphosphonates

- bisphosphonates are synthetic analogues of pyrophosphate, characterized by a phosphorus-carbon-phosphorus bond which renders them resistant to hydrolysis

- intestinal absorption is poor ( $<1 \%$ to $10 \%)$, plasma clearance rapid, and skeletal half-life long

- bisphosphonates have inhibitory effects on bone resorption and bone mineralization; the potency of these effects varies greatly with different compounds

Box 2

into bone, and urinary excretion. ${ }^{12}{ }^{13}$ Therefore, in these cases the toxicity seems to be related to the subacute effects of bisphosphonates.

As far as we know, this is the first report of ototoxicity after oral administration of etidronate. Although the bioavailability of orally administered bisphosphonates is poor, their half-life in the skeleton is very long. Our patients suffered tinnitus and severe hearing loss after the fifth month of therapy.

Although bisphosphonates are commonly used in various clinical conditions, ototoxicity is clearly a rare complication. However, it may be more frequently observed in the future as a result of a substantial increase in bisphosphonate use. Ototoxicity is a potentially serious side-effect because it can result in permanent sequelae, as in our patients. Increased awareness of this probable side-effect will make early diagnosis of ototoxicity possible and allow discontinuation of therapy if necessary. Patients with pre-existing ear pathology should be monitored audiometrically so that ototoxicity can be recognised earlier during bisphosphonate therapy, thus improving the long-term outcome of an affected patient.

8 Causse JR, Causse JB, Bretlau P, et al. Etiology of otospongiotic sensorineural hearing loss. Am f Otol 1989;10:99107.

9 Elonka DR, Applebaum EL. Otosclerotic involvement of the cochlea: a histologic and audiologic study. Otolaryngol Head Neck Surg 1981;89:343-51.

10 Kennedy DW. The effects of etidronate disodium on progressive hearing loss from otosclerosis. Otolaryngol Head Neck Surg 1993;109:461-7.

11 Fleisch $\mathrm{H}$. Bisphosphonates: mechanisms of action and clinical use in osteoporosis-an update. Horm Metab Res 1997;29:145-50.

12 Fleisch $\mathrm{H}$. Bisphosphonates in bone disease. From laboratory to the patient. 2nd edn. London: The Parthenon Publishing Group, 1995; pp 57-62.

13 Pongchaidecha $M$, Daleyyates PT. Clearence and tissue uptake following 4-hour and 24-hour infusions of pamidronate in rats. Drug Metab Dispos 1993;21:100-4. 